\title{
Ideological Paradigms and Their Impact on Environmental Problems Solutions in Coal Mining Regions
}

\author{
Vladimir Zolotukhin ${ }^{1, *}$, Natalia Zolotukhina ${ }^{2}$, Maria Yazevich ${ }^{1}$, Alexey Rodionov ${ }^{1}$, and \\ Marina Kozyreva ${ }^{1}$ \\ ${ }^{1}$ T.F. Gorbachev Kuzbass State Technical University, Department of history, philosophy and social \\ sciences, 65000028 Vesennya st., Kemerovo, Russia \\ ${ }^{2}$ T.F. Gorbachev Kuzbass State Technical University, Department of chemistry and technology of \\ inorganic substances, 65000028 Vesennya st., Kemerovo, Russia
}

\begin{abstract}
The work presents the analysis of the influence of the ideological paradigms of technology in solving environmental problems in the conditions of modernization of production, where a significant role is given to the protection and preservation of the natural environment and the protection of the rights of a citizen to a favourable environment. The attention is focused on the fact that in a civilized society, the needs of the individual and society are formed within the right social and cultural fields. The main importance of the regulation of everyday reality allotted to the phenomenon of law as a certain ideological paradigm. Stressed that at different stages in the coexistence of ideology and power detected General forms and principles of their influence on social practices, and on consciousness. The article substantiates the position that any interaction of subjects of economic activities leads to the existence of "constructive tension".
\end{abstract}

\section{Introduction}

In the conditions of social transformation, a significant role is assigned to the protection and preservation of the natural environment [1-3], the protection of the rights of a citizen to a favourable environment especially for the problems associated with the introduction of new technologies for modernization of industrial enterprises [4-5].

The solution to these problems should be accompanied by a change of legislation at both the Federal and at the regional level, moreover, having the status of "coal producing regions". A well-developed legal framework in the sphere of protection of the environment, within a particular ideological paradigm. On the one hand, the fact that recognition of the possible coexistence of ideological paradigms and the multidimensionality of the social environment allow to speak about existence of the boundaries of the regional society awareness of environmental issues. On the other hand it is accompanied by certain institutional bodies implementation and monitoring of government regulations.

\footnotetext{
* Corresponding author: zvm64@mail.ru
} 


\section{Materials and Methods}

To study the influence of the ideological paradigms of technology in solving environmental problems was used to work C. Taylor, M. Weber, Parsons, M. A. Barg, etc. To identify specific relations of ideology and power, ideology and knowledge, as well as the role and importance of it in society contributed to the work of J. Lyotard, M. Foucault, B. Latour, J. Habermas. Analyzed the works and normative and legal acts in the field of environmental protection and the protection of human health and helped to identify the most important social phenomena and methodological characteristics specific to current research in this area. In describing the modern approaches to the consideration of ideological paradigms, their influence on the solution of ecological problems and to identify characteristics of the specific changes of modern technologies, methods were applied: comparative and rationallogical analyses, structural-functional approach, conceptual analysis, historical and logical.

\section{Results and Discussion}

In a civilized society, the needs of the individual and society are formed within the right and socio-cultural fields, In this regard, corporate ethics and rules of social behavior are the regulators of this interaction. The main importance of the regulation of everyday reality allotted to the phenomenon of law as a certain ideological paradigm.

In the study, under the ideological paradigm (ideology) in the tradition of Karl Marx and Karl Mannheim we understand the illusory form of consciousness, which expresses the interests of certain social groups. The essential features are its irrational and symbolic in nature, dominated by emotional, fantasised and figurative and symbolic components, which makes the ideology is largely similar to the myth and religion (E. Taylor, M. Weber, Parsons, M. Barg, S. Zhizhek, W. Matts, A. Shils, etc.).

In works of J. Lyotard, M. Foucault, B. Latour, A. Kravets, E. Mamchur and others, focuses on the relations between ideology and power, ideology and knowledge, ideology and policy, questions about the role and importance of it in society. It should be emphasized that at different stages in the coexistence of ideology and power can be used to detect a number of General forms and principles of their influence on social practices. The use of certain means and methods of influence on social consciousness [7], the promotion of their own interests, as well as ways to achieve economic, legal and political goals.

Draws attention to the fact, that the classical ideology of liberalism is the result of certain philosophical doctrines, social needs and economic processes. It is based on the principles of pragmatism, individualism, which contributes to the implementation needs of the community of entrepreneurs in the conditions of emerging capitalism in the tradition of $\mathrm{K}$. Marx, M. Weber, K. Mannheim and others, which is the formation of a special installation relations of man to the world, where it manifests its desire to "set the measure of things" [6] and to control reality.

The recognition of ideological pluralism and multidimensionality of the social environment [9] in various aspects of its manifestation (socio-economic [18], environmental [10, $11]$, technology $[8,17]$, management $[11,15]$, etc.) with the existence of differences and contradictions (defining the ontological possibility of conflict) allow to speak about presence of edges in the awareness of environmental issues (environmental space) as a measure of their certainty. This is due to the presence and/or absence of environmental consciousness, the need of defining the boundaries of "Green ecology" in the framework of the mutual interest of the different actors in its formation from the point of view of manifestations of citizenship with the balance of incentives and penalties.

Having distinctive values and semantic units, each ideological paradigm (ideology - liberal, conservative and socialist (communist), etc.) is focused on creating specific to the state 
and/or territorial entity rational-logical concept descriptions of social life, in particular specific paradigm of ecological space. This paradigm requires the availability and the possibility of using not only theoretical and conceptual apparatus, but also of modern technologies in the field of ecology. The reality is not only knowable, but "used" by man. Of particular importance here is the "historicity" of human existence, the certainty of his place and time the "situation" in which man finds himself, including at the national and ethno-geographic levels.

Every interaction of subjects of economic activities leads to the existence of "constructive tension" (A. Akhiezer). In this society, including its environment (natural, technological, etc.) should be implemented the possibility of its preservation against the flow of entropy processes. In this case actualizarea the need of seeking consensus as a form of activities on the basis of a recognised (accepted) by all of the rules in the dialectical opposition. Consensus as the absorber of social tensions is implemented in socio-economic activities and contributes to the compromise of all interested parties (economic entities, bodies of state and municipal government and administration, citizens, civil society, etc.). A compromise based on the recognition of certain common interests and strategic objectives is achieved through consensus as a specific form of resolution of environmental conflicts. Consensus involves understanding that the satisfaction of their own interests possible in light of the interests of the "other". In the foreground the anthropological nature of the struggle for the preservation not only within society but also the environment of man himself and his entourage. On this basis, actualizarea the problem of choice of values in one (liberal) or more ideological paradigms.

The preservation and reproduction of values is possible within the socio-cultural space, including the legal culture. Under consideration of the relationship of social injustice in society, it deals with "cultural or symbolic" (Frager N.) injustice. The latter expresses the prevailing cultural domination of one (the forms) of culture on the other, the nonrecognition of a particular cultural tradition in terms of the dominant culture and finally contempt, i.e., the systematic negative stereotyping and discrimination of a particular cultural practice in the field available to the mass culture [18]. The elimination of this type of injustice linked with transformation of a common cultural environment, transformation, which is based on the principles of recognition and support of cultural diversity. Within reach mutual consensus, in the words of $M$. T. Stepanyants "played a significant role, a sober based on the survival advantage of both the contending parties by refraining from the usual at "meetings" of civilizations strategy for the physical destruction of "hostile parties" and the violent eradication of its culture. There was a preference for gradual reconciliation through tactics of inclusion" [12]. That is another proof of the idea that there are no rules and regulations cannot be taken in finished form - they must be checked, missing person through itself, through its constructive experience.

Kemerovo region takes a leading position in coal production in Russia, which, ultimately, indicates the high ecological fragility of the region. It should be noted that a high level of development of the coal and mining industry has no less negative impact and the landscape of Kuzbass. We are talking primarily about the "ridges" dumps, runs through the whole territory of Kemerovo region. According to the 2014 disturbed area in the given subject of the Russian Federation is not less than 100 thousand hectares, which is $10 \%$ of the territory of the Kuzbass coal basin. In addition, the resulting tailings mountain parody pollute the air considerably as a result of weathering. One of the methods in the current technological situation can be land reclamation, namely, artificial reforestation of the resulting coal dumps [17].

Today, the reclamation of "carbon ranges" as the method of recovery of disturbed ecosystems, in this applied subject. In the Kuzbass, attempts were made to create a structure dedicated to the management and control of the reclamation of land disturbed by coal min- 
ing. So, was organized by the Fund of assistance to the coordination Council for development of the coal industry, labor protection, industrial and environmental safety in the Kemerovo region [15], but in October 2013 the Fund was liquidated.

Land reclamation is carried out at the expense of businesses engaged in coal mining (in 2016 - 126 million rubles., in 2017 it was planned for approximately 400 million rubles). It is also planned to apply new methods of remediation that will definitely improve the quality of the human environment.

Thus, under the decision of environmental problems in coal mining regions is important to consolidate the legal regulation of the ecological situation in coal mining regions, to create funds for the promotion of reclamation of disturbed lands within the existing Association of coal enterprises, to amend relevant regulations in the Russian Federation.

The notion of strategic action Habermas combines the concept of action in accordance with the economic interests and the concept of purposeful rational action. In its framework people focus solely on the success and the results of their actions, they seek to exert economic pressure and other means of coercion on others. Strategic action involves the categories of power, wealth, institutions, purposes. Communicative action is oriented to reconciliation, mutual understanding and recognition in the negotiating process. This idea is very relevant for Russia, where democracy is often understood as "majority rule". Meanwhile, as he wrote Titus Livy: the "Free state, one in which... all citizens are equal participants in the rule of law. This is a self-governing community in which the greater Empire of laws the Empire of man" [14]. Protection of minorities is the protection of their competition (political), and maintain consensus on major issues as a minority - one of the sources of public maneuverability, mobility.

In the annual report of the Federal service for supervision of consumer rights protection and human welfare provides information about the state sanitary-and-epidemiologic wellbeing of the population in the Russian Federation, including focuses on the fact that in recent years the workers of enterprises on extraction of mineral resources noted the highest weight was registered for the first time occupational diseases $-43.03 \%$. Indicators of occupational morbidity, exceeding the figure for the Russian Federation (of 1.47), as in previous years, marked in the Kemerovo region (of 13.24). It is also noted that, if the whole of the Russian Federation of managerial decisions in the field of environmental protection and the evaluation of health risk was $4.7 \%$ (118), in relation to the Kemerovo region as one of the subjects it is $12 \%$ [12].

As an example, it can be noted that in the framework of the "Charter of the Kemerovo region" with the implementation of the rights of citizens to a favourable environment, the public authorities of the Kemerovo region carried out a number of measures: adoption of laws and other normative legal acts of the Kemerovo region in the field of environmental protection; the establishment of standards of environmental quality; the adoption and implementation of state programs of the Kemerovo region, etc. The division of powers between bodies of state power of the Kemerovo region in the sphere of environmental protection defined in the Law of the Kemerovo region from 18 January 2007 "On the delimitation of powers between public authorities of the Kemerovo region in the sphere of environmental protection". In the framework of the state program of the Kemerovo region "Ecology and natural resources of Kuzbass" for 2014-2018 and "Ecology, subsoil use and water management" in 2017-2019 find the resolutions for the issues of sustainable economy mineral resources and geological information on mineral resources; improve the environmental safety and the preservation of natural systems, etc.

At the level of methodical recommendations establish uniform approaches to development and General requirements to the content and formatting of draft standards for waste and limits on their placement, the Regulations of the Board of administration of the Kemerovo region (03.12.2012 No. 534, 16.09.2014 No. 359) defines the General rules of con- 
ducting of works on regulation of emissions of harmful (polluting) substances in atmospheric air during the periods of adverse meteorological conditions; the procedure for the exploration and production of common mineral resources by the subsoil users. Also defined a list of normative legal acts containing mandatory requirements, evaluation of compliance with which is subject to state control (supervision). [12]

It should also pay attention to the fact that within the "paradigm of directed evolution of the biosphere" (A. V. Yablokov) [16] includes not just the awareness of the catastrophic situation that is associated with the environment, but also the development of specific activities and technologies contribute to overcome the key factors, which are the carriers of ecological contradictions. From a number of factors can be identified such as: "the impact of the accumulated anthropogenic high-frequency radiation, chemical substances that are not inherent in nature, and, as a consequence, the growth in the number of people with pathological disorders" and "the speed of concentration and commissioning resources in solving problems of national scale". Timely response to the emergence and diagnosis of dangerous situations, makes it possible to timely prevent, catastrophic development and education of local man-made disasters.

\section{Conclusion}

Thus, the influence transmitted through the public authorities at both the Federal and territorial levels of ideological paradigms related to the solution of environmental problems, the processes of enterprises modernization and introduction of modern technologies, in particular, contributing to the preservation and restoration of the environment. Emphasized the role and importance of legal culture at all stages of enforcement: discussion, adoption of laws and normative legal acts, their application in various fields, as well as forms and methods of monitoring their performance from the interested in this subject not only economic activities, but also society as a whole.

\section{References}

1. M.I. Agienko, E.P. Bondareva, G.V. Chistyakova, O.V. Zhironkina, O.I. Kalinina, IOP Conf. Ser.: Earth Environ. Sci., 50:1, 012022

2. M. Tyulenev, E. Garina, A. Khoreshok, O. Litvin, Y. Litvin, E. Maliukhina, IOP Conf. Ser.: Earth Environ. Sci., 50:1, 012035 (2017)

3. M. Tyulenev, S. Zhironkin, K. Kolotov, E. Garina, Poll. Res. 35:2, 221-227 (2016)

4. E. Dotsenko, N. Ezdina, E3S Web of Conf., 15, 04012 (2017)

5. V. Trifonov, O. Loyko, D. Nesteruk, S. Zhironkin, E. Strekovtsova, AIP Conf. Proceed., 1800, 050009 (2017)

6. I.V. Chernikova, Epistemological schemas and their role in scientific knowledge. Epistemology: the main problems and the evolution of approaches in philosophy of science (Kemerovo: Kuzbass state technical University, 2007)

7. M.T. Stepanyants, Voprosy Filosofii, 8, 20-30 (2017)

8. A.B. Efremenkov, A.A. Khoreshok, S.A. Zhironkin, A.V. Myaskov, IOP Conf. Ser: Earth Envir. Sci. 50:1, 012009 (2017)

9. N. Fraser, From redistribution to recognition Dilemmas of justice in a post-socialist age (London, New Left Review, 1995)

10. T.V.Galanina, M.I. Baumgarten, V.G. Mikhailov, T.G. Koroleva, G.S. Mikhailov, IOP Conf. Ser: Earth Envir. Sci. 50:1, 012030 (2017) 
11. T.V Kiseleva, V.G. Mikhailov, V.A. Karasev, IOP Conf. Ser: Earth Envir. Sci. 45, 012013 (2016)

12. S.S. Nipa, The almanac of the Center for social Sciences and the faculty of Economics of MSU named after M. V. Lomonosov, 4:112, 57-63 (2017)

13. On the state sanitary and epidemiological wellbeing of the population in the Russian Federation in 2016: State report (Moscow, Federal service for supervision of consumer rights protection and human welfare, 2017)

14. Q. Skinner, Liberty Before Liberalism (Cambridge, CPress, 1998)

15. V. Trifonov, O. Loyko, D. Nesteruk, S. Zhironkin, E. Strekovtsova, AIP Conf. Proceed. 1800, 050009 (2017)

16. A.V. Yablokov, V.F. Levchenko, A.S. Kerzhentsev, Philosophy \& Cosmology, 14, 3445 (2015)

17. S.A. Zhironkin, K.A. Kolotov, A.E. Genin, F.V. Agafonov, S.A. Kovalevsky, IOP Conf. Ser: Earth Envir. Sci. 50:1, 012011 (2017)

18. V.M. Zolotukhin, V.A. Gogolin, M.Yu. Yazevich, M.I. Baumgarten, A.V. Dyagileva, IOP Conf. Ser: Earth Envir. Sci. 50:1, 012027 (2017) 